\title{
Power Loss Comparison of Single- and Two-Stage Grid- Connected Photovoltaic Systems
}

\author{
M. Praveenkumar ${ }^{\# 1}$, Ms. S. Jayachitra ${ }^{* 2}$ \\ ${ }^{\# 1}$ PG Scholar Kingston Engineering College Tamilnadu dist India \\ ${ }^{*}$ Assistant Professor Kingston Engineering College Tamilnadu dist India \\ Department of Electrical and Electronics Engineering
}

\begin{abstract}
This paper presents power loss comparison of single and two-stage grid-connected photovoltaic (PV) systems based on the loss factors of double line-frequency voltage ripple (DLFVR), fast irradiance variation + $D L F V R$, fast dc load variation + DLFVR, limited operating voltage range + DLFVR, and over-all loss factor combination. These loss factors will result in power deviation from the maximum power points. In this paper, both single-stage and two-stage grid-connected PV systems are considered. All of the effects on a two-stage system are insignificant due to an additional maximum power point tracker, but the tracker will reduce the system efficiency typically about 2.5\%. The power loss caused by these loss factors in a single-stage gridconnected PV system is also around 2.5\%; that is, a single-stage system has the merits of saving components and reducing cost, and does not penalize overall system efficiency under certain operating voltage ranges. Simulation results with the MATLAB software package and confirmed the analysis.
\end{abstract}

Index Terms: Loss factor, power loss comparison, single-stage grid-connected photovoltaic (PV) system, twostage grid-connected PV system.

\section{Introduction}

Photovoltaic (PV) grid-connected systems based on a two-stage configuration have been widely studied. Recently, PV dc-distributed systems, as shown in Fig. 1, with either a single-stage configuration [saving an maximum power point tracker (MPPT) stage] or a two-stage one have been being emerging [1]. They can draw maximum power from PV modules and inject the power into utility grid with unity power factor or they can rectify the ac source to replenish and regulate the dc bus. However, the loss factors, such as operational conditions, components, and grid voltage, will deviate effective PV output power.

In a grid-connected PV system (GCPVS), PV power varieswith operational conditions, such as irradiance, temperature, light incident angle, reduction of sunlight transmittance on glass of module, and shading [2]-[5], [12], [13]. These factors have been investigated in detail and the authors have presented diagnosis methods to estimate the reduction of PV power. Moreover, a special condition, snow coverage, has been also discussed [6], which was compared with other coverage situations such as shading and dirt. Then, another loss factors, such as components, solar cell serial resistance, and capacity loss in PV batteries, have been reported [3], [7], [8], [19], which are related to the cells themselves. During system operation, there are loss factors such as double line-frequency voltage ripple (DLFVR) due to ac grid [9], [10], [14]-[17] and fast irradiance variation [11], causing deviation from the maximum power points (MPPs) and also resulting in power loss. However, these factors have not been taken into account in power loss comparison for both single-stage and two-stage GCPVS.

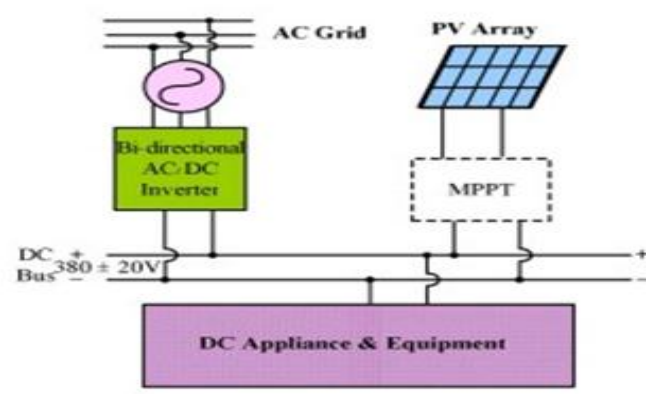

Fig. 1. Block diagram of a PV dc-distributed system.

This paper presents power loss comparison according to five loss factors that might deviate the operating points from the MPPs. First, this paper conducts modeling of solar cells and numerical analysis including I-V characteristics of PV modules to derive the effect of DLFVR on both single-stage and two-stage 
GCPVS. Then, it performs power loss analysis due to fast irradiance variation. Moreover, a single-stage PV system will penalize its output power under certain operating voltage ranges, while it can save an MPPT stage. In a PV dc-distributed system, as shown in Fig. 1, its dc-bus voltage is regulated by the bidirectional inverter

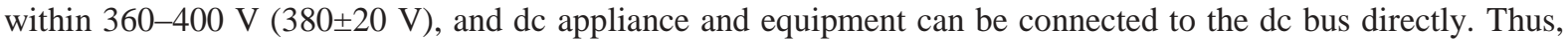
this study chooses "fast dc load variation" and "limited operating voltage range" as two of the loss factors. Since the effect of DLFVR exists all the time, this paper presents the five loss factors as "DLFVR," "fast irradiance variation + DLFVR," "fast dc load variation + DLFVR," "limited operating voltage range + DLFVR," and "overall loss factor combination."

\section{Modelling Of Pv Arrays}

This section models a PV array, consisting of 14 in series and 2 in parallel PV modules (APOS Series AP-220) for a single-stage GCPVS or 7 in series and 4 in parallel for a two-stage GCPVS. The power loss analysis based on the loss factors will be then presented in the next section. An equivalent circuit of a solar cell is shown in Fig. 2, in which the current source Isc is the light-induced current, $\mathrm{Rj}$ is the nonlinear resistance in the $\mathrm{P}-\mathrm{N}$ junction, $\mathrm{Dj}$ is the $\mathrm{P}-\mathrm{N}$ junction diode, Rsh and $\mathrm{Rs}$ stand for internal equivalent parallel and series resistance, respectively, Ro is the output load, and ipv and vpv are the output current and voltage of the solar cell, respectively [18]. For simplifying the analysis, Rsh, Rs , and Rj are ignored. Therefore, the output current ipv of the solar cell can be expressed as

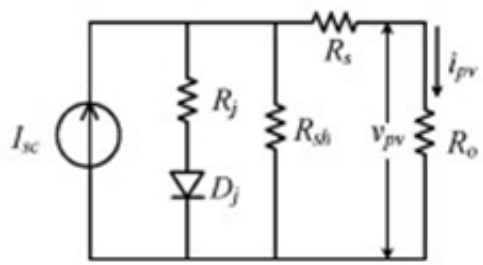

Fig. 2..Equivalent circuit of a solar cell.

where $\mathrm{np}$ is the number of solar cells in parallel, ns is the number of solar cells in series, $\mathrm{q}$ is the electric charge $(1.6 \times 10-19 \mathrm{C}), \kappa$ is the Boltzmann constant $(1.38 \times 10-23 \mathrm{~J} / \mathrm{K} \circ), \mathrm{T}$ is the temperature of solar cells (in degrees Kelvin), and $\mathrm{A}$ is the diode ideal factor $(\mathrm{A}=1-5)$. Additionally, Isat stands for the reverse saturation current and can be expressed as

The saturation current Isat is a function of temperature $\mathrm{T}$. In (2), $\mathrm{Tr}$ is the reference temperature of the solar cell, Irr is the reverse saturation current at $\mathrm{Tr}$, and Egap is the band gap of the solar cell (in electronvolts). Moreover, the light-induced current Isc changes with irradiance and temperature, which can be expressed as

where the current Isso is the short-circuit current at reference temperature $\mathrm{Tr}$ and a specific irradiance $(1000 \mathrm{~W} / \mathrm{m} 2), \mathrm{Ki}$ is the temperature coefficient of a short-circuit current, and $\mathrm{Si}$ is the irradiance $(\mathrm{W} / \mathrm{m} 2)$. Table I lists the parameters of the APOS Series AP-220 PV module [20], which are used in (1)-(3). By tuning the ideal diode factor $\mathrm{A}=1.8$ and energy band gap Egap $=1.4 \mathrm{eV}$, a PV module can be then simulated and compared with a real module, as shown in Fig. 3. It can be observed that the simulated results are relatively close to the real ones, which can ensure accuracy of the following analysis.

\section{Analysis Of Power Loss}

This section presents power loss analysis of both single-stage and two-stage GCPVS, which includes the effects of DLFVR, fast irradiance variation + DLFVR, fast dc load variation + DLFVR, limited operating voltage range + DLFVR, and overall loss factor combination. The analysis is based on the simulated PV array model shown in Figs. 2 and 3.
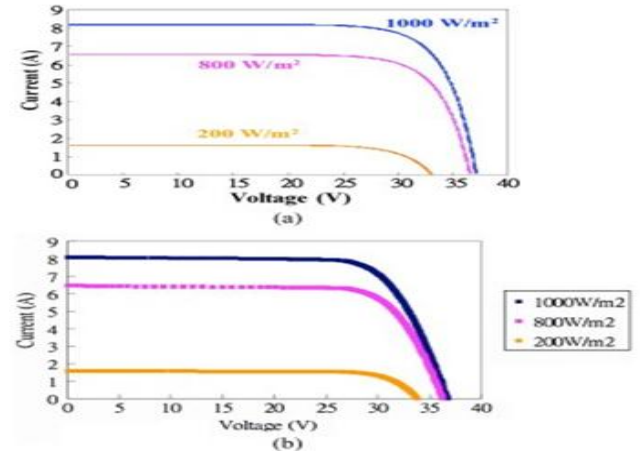

Fig. 3. PV module I-V characteristics of (a) simulated module and (b) real one (APOS Series AP-220). 
TABLE I

SPECIFICATIONS OF THE 220-W SOLAR MODULE (APOS SERIES AP-220)

\begin{tabular}{|l|l|}
\hline \multicolumn{1}{|c|}{ Parameter } & \multicolumn{1}{c|}{ Value } \\
\hline Peak Power $(+i-5 \%) P_{\text {aver }}$ & $225 \mathrm{~W}$ \\
\hline Rated Voltage $V_{\text {mage }}$ & $29.13 \mathrm{~V}$ \\
\hline Rated Current $I_{\operatorname{meg}}$ & $7.77 \mathrm{~A}$ \\
\hline Open Circuit Voltage $V_{e c}$ & $37.08 \mathrm{~V}$ \\
\hline Short Circuit Current $I_{\kappa}$ & $8.20 \mathrm{~A}$ \\
\hline Temperature Coefficient of Voltage & $-0.37 \% /{ }^{\circ} \mathrm{C}$ \\
\hline Temperature Coefficient of Current & $0.07 \% /{ }^{\circ} \mathrm{C}$ \\
\hline
\end{tabular}

\section{A. DLFVR}

1) Single-Stage GCPVS: The circuit configuration of a single-stage GCPVS is shown in Fig. 4. When the system reaches the maximum power point Pm pp under a specific irradiance, its PV voltage vpv and current ipv become constant and equal to Vm pp and Im pp, respectively. However, the effect of DLFVR on the deviation of PV voltage away from Vm pp will cause power loss, which can be expressed as

Here, $\mathrm{Tl}$ is the line period and Ts is the switching period of the full-bridge inverter. Expressions for vpv and ipv are derived first, and then the power loss can be determined. Voltage vpv can be expressed as

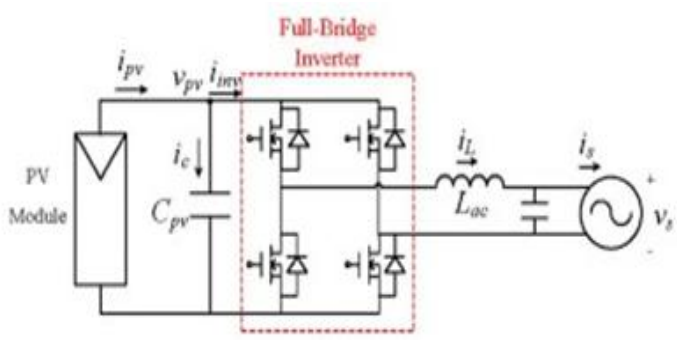

Fig.4.Circuit configuration of a single-stage GCPVS

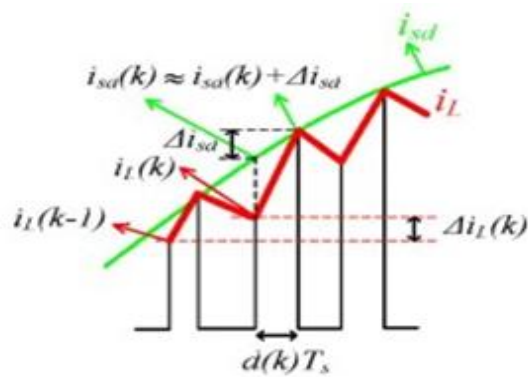

Fig.5. Conceptual current waveforms of isd, iin, and iL .

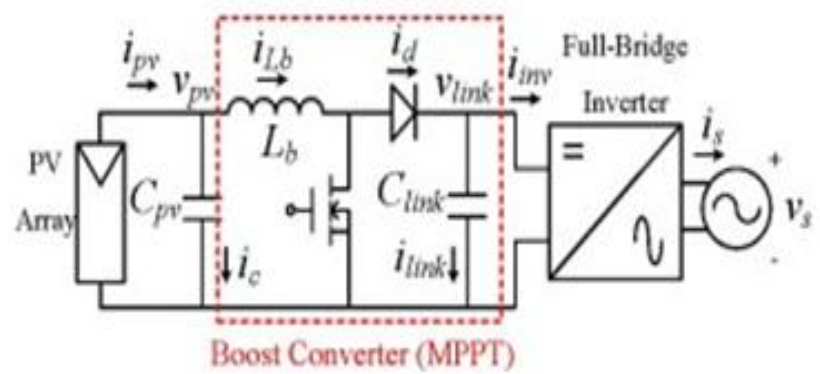

Fig.6. Circuit configuration of a two-stage GCPVS with a boost converter functioning as an MPPT.

and current iinv stands for the inverter input average current. PV voltage vpv will vary with input capacitance $\mathrm{Cpv}$, the difference between current ipv and iinv, and switching period Ts. Additionally, current ipv will change with vpv. From (1), we can obtain a numerical expression for ipv :

In general, an inverter system is operated by a current control at a fixed frequency $1 / T$ s . Even though 
the system reaches the MPP, its inductor current iL still has a current ripple; that is, the uperbound current command isd can be set to $\alpha \times$ is for an inverter-inductor current iL to track, as shown in Fig. 5, where $\alpha$ is a real number larger than unity. Moreover, the circuit shown in Fig. 4 is operated as a buck converter to shape the inductor current to be sinusoidal and in phase with the ac grid voltage. Thus, the inverter input average current iinv can be approximated by a multiplication of the output current is and the duty ratio $d$ in every switching cycle Ts, which can be expressed as

From the aforementioned equations, we can determine the turn-on time interval as follows:

where Lac is the inverter inductor and vs is the ac-grid voltage. As From (1) to (8), the total power loss Ploss deviating from the MPP during one line period $(1 / 60 \mathrm{~Hz})$ can be estimated.

2) Two-Stage GCPVS: Circuit configuration, with a boost converter functioning as an MPPT, of a two-stage GCPVS is shown in Fig. 6. With the boost converter, the operating voltage vpv of the PV modules can be lower than the dc-link voltage vlink. For comparing both single-stage and two-stage systems, inverter parameters are kept identical. The expression of the PV current ipv is the same as (6), and the variation of the PV voltage vpv is the same as (4) except the inverter input current iinv, which is replaced with the inductor current iLb . Determination of the boost inductor current iLb is illustrated in Fig. 7. Before the next perturbation of maximum power point tracking, it is necessary to regulate the average value of iLb equaling the MPP current Im $\mathrm{pp}$. Therefore, we can adopt an average method to determine iLb where the average value of iLb equals Im pp during turn-on interval db Ts. It can be expressed as

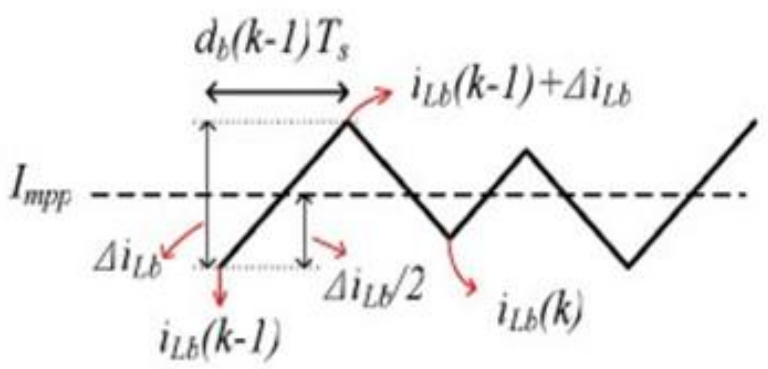

Fig.7. Illustration of inductor current iL b varying with time.

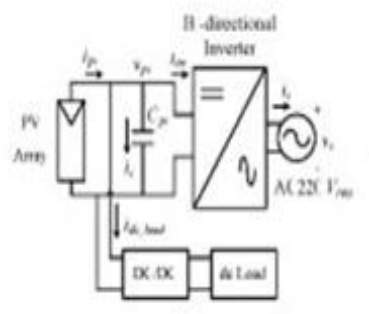

(a)

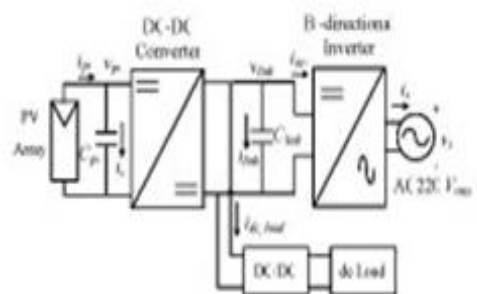

(b)

Fig.8. Block diagrams of (a) single-stage and (b) two-stage GCPVS with dc load

Additionally, similar to (5), variation of the dc-link voltage vlink can be analogously related to the input diode current id and PV current ipv. Power loss analysis according to the loss factor of DLFVR can be attained from (6), (7), (9), and (10).

\section{B. Fast Irradiance Variation + DLFVR}

The output power of a PV array is strongly dependent on irradiance and temperature, where irradiance would change rapidly in a cloudy day. A cloud passing over PV modules will cause operating point deviating from the MPP and resulting in power loss. The power loss analysis based on fast irradiance variation and DLFVR will include the relationship between PV array output current and irradiance. Then, by setting the change of irradiance $\Delta$ Si over one line period $(1 / 60 \mathrm{~Hz})$ and combining (1)-(3) with the analysis of DLFVR, as well as the effect of fast irradiance variation on PV voltage vpv , the power loss Ploss can be determined as

\section{Fast DC Load Variation + DLFVR}

Fig. 8 shows block diagrams of a single-stage and a two-stage GCPVS with dc load. When the dc load starts to absorb power, the capacitor current ic will drop and the PV voltage vpv will drop correspondingly. The PV voltage vpv then will deviate from the MPP and result in power loss. By setting the required power Pdc for dc load and rising time Trise from no load to the full load, the expression for dc load power pdc load is shown as 
follows:

From (12), we can obtain the dc load current

Analysis of power loss due to fast dc load variation can be accomplished from (12) and (13), and based on the derivation of DLFVR.

\section{Limited Operating Voltage Range + DLFVR}

If a single-stage GCPVS is applied to a dc microgrid power distribution system, its operating voltage range of PV arrays is limited within 360-400 V. In general, an MPP voltage changes with irradiance and temperature. Therefore, $\mathrm{Pm}$ pp is expressed as $\mathrm{Pm} p \mathrm{pp}(\mathrm{Si}, \mathrm{T})$, and it is identical to (4).

\section{E. Overall Loss Factor Combination}

Since all loss factors are not independent except the effect of DLFVR, the power loss cannot be summarized from each individual one. Therefore, combing all loss factors together to analyze the total power loss is necessary. With (1)-(8), the over- all power loss due to these loss factors can be then calculated.

\section{Analysis And Simulation Procedure}

This section summarizes the procedure of the power loss analysis and its simulation. By following the procedure, one can conduct power loss analysis of a given PV array and a GCPV system according to the aforementioned loss factors. The

TABLE II

OPERATING CONDITIONS OF THE TWO PV SYSTEMS

\begin{tabular}{|l|c|c|}
\hline $\begin{array}{l}\text { Operating } \\
\text { Conditions }\end{array}$ & $\begin{array}{c}\text { Single-Stage } \\
\text { GCPVS }\end{array}$ & $\begin{array}{c}\text { Two-Stage } \\
\text { GCPVS }\end{array}$ \\
\hline Irradiance $S_{t}$ & $1000 \mathrm{~W} / \mathrm{m}^{2}$ & $1000 \mathrm{~W} / \mathrm{m}^{2}$ \\
\hline Temperature $T$ & $60{ }^{\circ} \mathrm{C}$ & $60{ }^{\circ} \mathrm{C}$ \\
\hline PV Capacitor $C_{p v}$ & $8^{*} 470 \mu \mathrm{F}$ & $470 \mu \mathrm{F}$ \\
\hline DC-Link Capacitor $C_{\text {ito }}$ & $\mathrm{N} / \mathrm{A}$ & $8 * 470 \mu \mathrm{F}$ \\
\hline $\begin{array}{l}\text { Inverter Switching } \\
\text { Frequency } T_{s}\end{array}$ & $20 \mathrm{kHz}$ & $20 \mathrm{kHz}$ \\
\hline $\begin{array}{l}\text { Boost Switching } \\
\text { Frequency } T_{s b}\end{array}$ & $\mathrm{~N} / \mathrm{A}$ & $20 \mathrm{kHz}$ \\
\hline Inverter Inductor $L_{\mathrm{sar}}$ & $2.5 \mathrm{mH}$ & $2.5 \mathrm{mH}$ \\
\hline Boost Inductor $L_{b}$ & $\mathrm{~N} / \mathrm{A}$ & $1.5 \mathrm{mH}$ \\
\hline
\end{tabular}

proposed modeling procedure can include both high-frequency and low-frequency voltage ripple and power loss. Moreover, the power loss analysis can be conducted with loss factors one by one. The procedure is described as follows.

1) Program array characteristic equations (1)-(3) into MATLAB and set parameters of a selected PV module, such as open-circuit voltage Vo c , short-circuit current Isc , and others from (1) to (3) except the ideal factor A and energy band gap Egap .

2) Tune $\mathrm{A}(\mathrm{A}=1-5)$ and Egap $($ Egap $\approx 1.1 \mathrm{eV})$ so that the simulated module model can fit the actual parameters, $\mathrm{Vm}$ pp, Im pp, and temperature coefficient $\mathrm{Kv}$ of the voltage.

3) Set operating conditions, such as $\mathrm{Cpv}$, Clink, irradiance, and temperature, and program the derivation of power loss caused by DLFVR, (1)-(10), into MATLAB.

4) Based on step 3), set a fast irradiance change rate $\Delta \mathrm{Si}$ and program the derivation of power loss caused by fast irradiance variation, (11).

5) Based on step 3), set dc load conditions, such as dc load power Pdc and the rising time Trise , and program the derivation of power loss caused by fast dc load variation, (12) and (13).

6) Base on step 2), set ten irradiance levels from 100 to $1000 \mathrm{~W} / \mathrm{m} 2$ and six temperature levels from 25 to $70 \circ \mathrm{C}$ to estimate the power loss caused by over limited operating voltage range, 360-400 V.

7) Finally, summarize the power loss due to the aforementioned loss factors for both single-stage and twostage grid-connected PV systems.

\section{Simulated And Measured Results}

This section shows simulated and measured results based on the power loss analysis, and the plots of power loss versus different operating conditions, such as irradiance, dc-link capacitance, and PV-side capacitance. In addition, the effects of the loss factors on both single-stage and two-stage GCPVS are discussed. Table II shows the operating conditions for the two systems. 


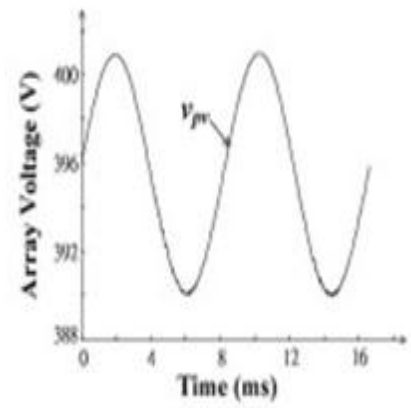

(a)

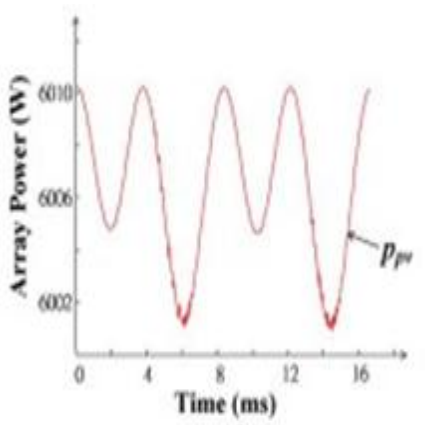

(b)

Fig. 9. Ripple waveforms of (a) PV array voltage v pv and (b) PV array output power ppv in a single-stage GCPVS when capacitor Cpv is fixed at $8 * 470 \mu \mathrm{F}$.

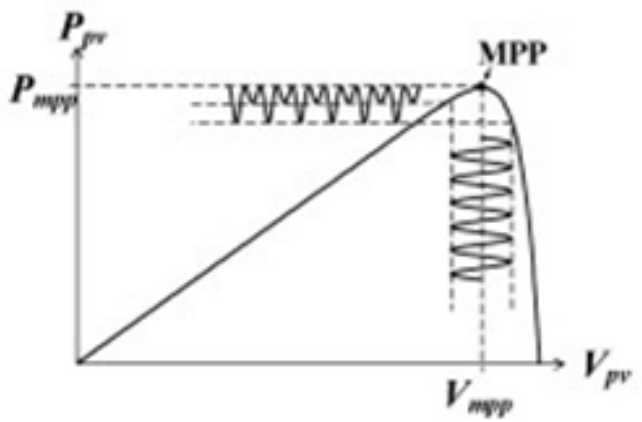

Fig.10. Illustration of a power ripple due to the effect of DLFVR

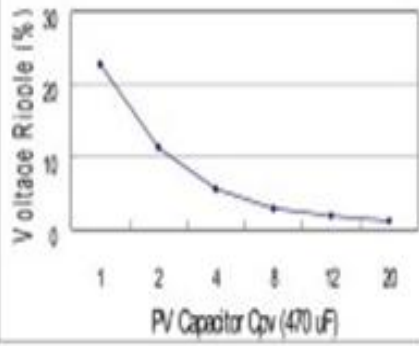

(a)

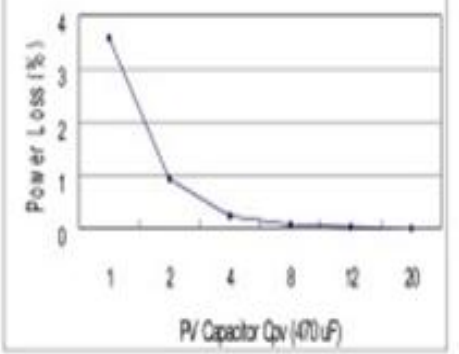

(b)

Fig. 11. Plots of PV capacitor Cpv versus (a) PV voltage-ripple percentage and (b) power-loss percentage in a single-stage GCPVS.

\section{A. Simulated Results}

1) DLFVR: For the operating conditions shown in Table II, we can obtain the waveforms of PV array voltage vpv, dc-link voltage vlink, and PV array output power ppv with MATLAB. The range of capacitor Cpv has six levels from $1 * 470 \mu \mathrm{F}$ to $20 * 470 \mu \mathrm{F}$ in a single-stage GCPVS. The waveforms of vpv and ppv can be simulated, as shown in Fig. 9, in which the system is operated with $\mathrm{Cpv}=8 * 470 \mu \mathrm{F}$. It can be observed that the magnitude of ppv is not constant, and its swing is much larger when vpv is located on the right-hand side of the MPP, which results from a steeper slope in the $\mathrm{P}-\mathrm{V}$ curve, as shownin Fig. 10. Then, by calculating the voltage ripple of $\mathrm{vpv}$ and the power loss, the plots of $\mathrm{Cpv}$ versus voltage-ripple percentage and power-loss percentage are illustrated in Fig. 11. The power loss due to double line-frequency in a single-stage PV system is about 3.5 $\mathrm{W}$ or $0.06 \%$ under $\mathrm{Cpv}=8 * 470 \mu \mathrm{F}$. For a two-stage GCPVS, the dc-link capacitor Clink is fixed to $8 * 470 \mu \mathrm{F}$, and the range of $\mathrm{Cpv}$ varies from 47 to $470 \mu \mathrm{F}$. Fig. 12 shows the ripple waveform of dc-link voltage vlink, PV array voltage $\mathrm{vpv}$, and its output power ppv with $\mathrm{Cpv}=470 \mu \mathrm{F}$. The voltage ripple of $\mathrm{vpv}$ and the power ripple are almost zero mainly due to switching-frequency; hence, the ripple effect can be ignored. Therefore, we can select PV capacitor $\mathrm{Cpv}=470 \mu \mathrm{F}$, which is sufficient enough to filter out the effect of DLFVR.

2) Fast Irradiance Variation + DLFVR: First, we consider that the speed of cloud is $30 \mathrm{~m} / \mathrm{s}$ passing over PV arrays, and its corresponding irradiance variation $\Delta \mathrm{Si} / \Delta \mathrm{t}$ being about $100 \mathrm{~W} / \mathrm{m} 2 / 16.6 \mathrm{~ms}$ and the PV array temperature being unchanged over one line cycle $(1 / 60 \mathrm{~Hz})$. According to the power loss analysis of fast 
irradiance variation, the ripple waveforms of PV voltage vpv and PV output power ppv can be simulated as shown in Fig. 13. For a large PV capacitor $\mathrm{Cpv}$, the change of vpv is only $3.8 \mathrm{~V}$, and the power loss is $3.67 \mathrm{~W}$ or $0.07 \%$. Because the change of $\mathrm{Vm}$ pp during $100 \mathrm{~W} / \mathrm{m} 2$ is only $2 \mathrm{~V}$, the operating voltage does not deviate from the MPP significantly. Therefore, the effect of fast irradiance variation on a single-stage GCPVS is not significant.

3) Fast DC Load Variation + DLFVR: For common dc home appliances, some like air conditioners consume high power above $500 \mathrm{~W}$ per set and others like lamps and computers just consume low power, below $300 \mathrm{~W}$. In the following, we assume that a set of dc load includes two air conditioners (the maximum power is $2000 \mathrm{~W}$ ), ten lamps (about $400 \mathrm{~W}$ ), two computers (about $500 \mathrm{~W}$ ), and the rising times of their power are $3 \mathrm{~min}, 1 \mathrm{~ms}$, and $0.5 \mathrm{~ms}$, respectively. That is, the fastest power variation is $1 \mathrm{~kW} / \mathrm{ms}$. Moreover, the operating conditions, $\mathrm{Cpv}=$ 8* $470 \mu \mathrm{F}$ for a single-stage GCPVS, and Clink $=8 * 470 \mu \mathrm{F}$ and $\mathrm{Cpv}=470 \mu \mathrm{F}$ for a two-stage GCPVS, are selected. The simulated results can be obtained from (12) and (13) with parameters Pdc $=1000 \mathrm{~W}$ and Trise $=1$ ms, as shown in Figs. 14 and 15, respectively. The power loss caused by a deviation from the MPP under fast dc load variation is $7.77 \mathrm{~W}$ on average or $0.13 \%$ in a single-stage GCPVS and $0.12 \mathrm{~W}$ or $0.002 \%$ in a two-stage GCPVS.

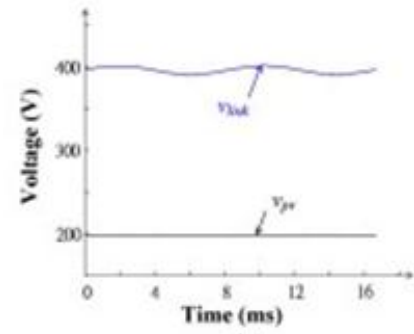

(a)

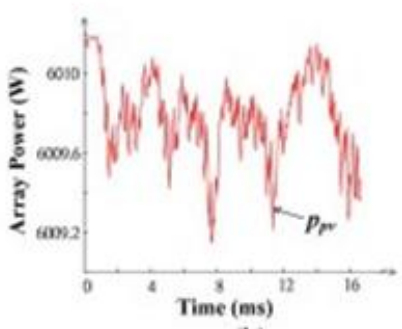

(b)

Fig. 12. Ripple waveforms of (a) voltages $\mathrm{v}$ lin $\mathrm{k}$ and $\mathrm{v} p \mathrm{p}$ and (b) PV array output power ppv in a two-stage GCPVS when a PV capacitor Clin $\mathrm{k}$ is fixed at 8* $470 \mu \mathrm{F}$ and $\mathrm{Cpv}$ is $470 \mu \mathrm{F}$.

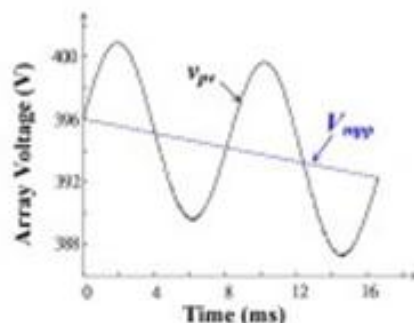

(a)

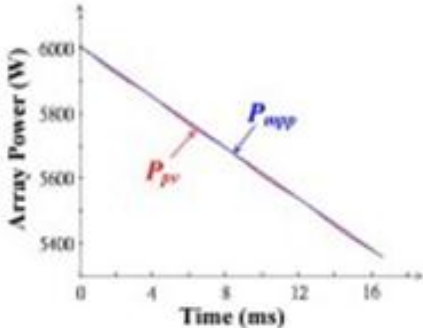

(b)

Fig. 13. The ripple waveforms of (a) PV array voltage and (b) PV array power in a single-stage GCPVS when fast irradiance variation is $100 \mathrm{~W} / \mathrm{m} 2 / 16.6 \mathrm{~ms}$.

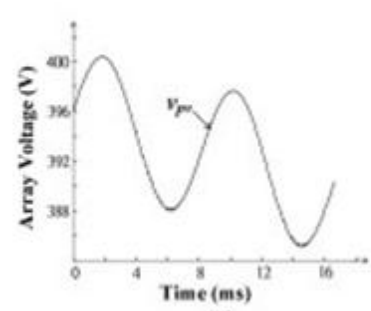

(a)

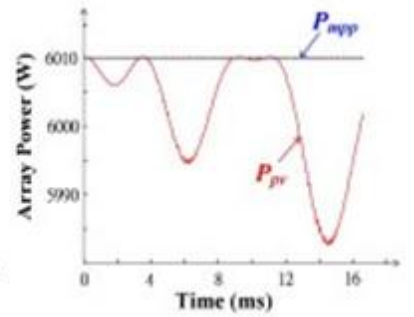

(b)

Fig. 14. Ripple waveforms of (a) PV array voltage and (b) PV array output power under fast dc load variation in a single-stage GCPVS. 


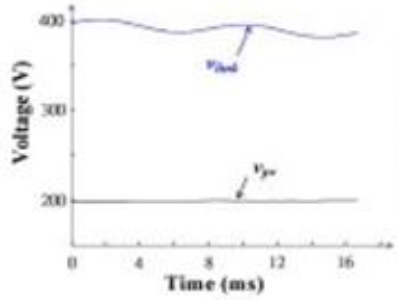

(a)

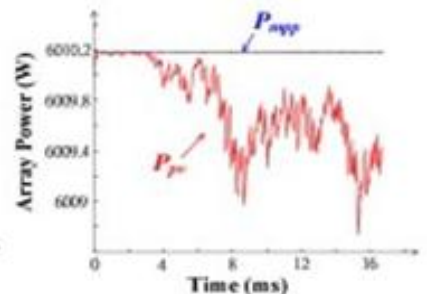

(b)

Fig. 15. Ripple waveforms of (a) voltages $v$ lin $k$ and $v$ pv and (b) PV array output power under fast dc load variation in a two-stage GCPVS.

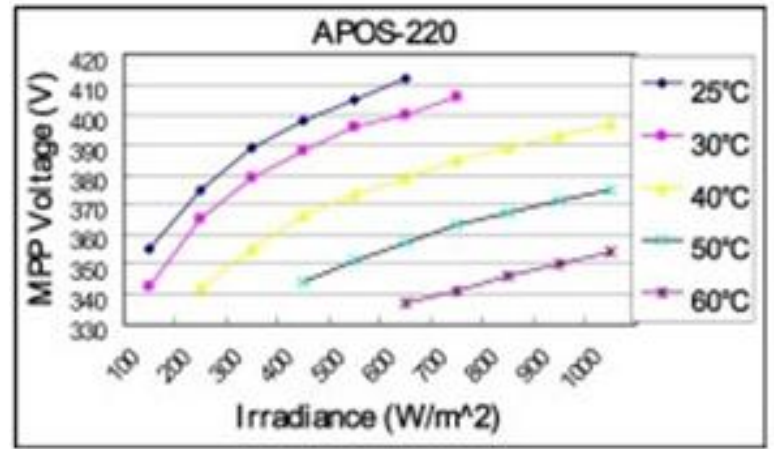

Fig. 16. Plots of irradiance versus the MPP voltage under the limited operating voltage range of $360-400 \mathrm{~V}$ with $14 \mathrm{PV}$ modules in series.

4) Limited Operating Voltage Range + DLFVR: As mentioned in Section II, the operating voltage Vm pp deviating out of the limited range, 360-400 V, will cause power loss. In the following, the power loss versus irradiance and temperature under the limited voltage range is investigated and illustrated. Note that infrequently occurring operating conditions are removed from the plots, since some temperature levels could not happen under certain irradiance, such as $25-30 \circ \mathrm{C}$ under $\mathrm{Si}=600-1000 \mathrm{~W} / \mathrm{m} 2,50 \circ \mathrm{C}$ under $\mathrm{Si}=100-400 \mathrm{~W} / \mathrm{m} 2$, and $60 \circ \mathrm{C}$ under $\mathrm{Si}=100-500 \mathrm{~W} / \mathrm{m} 2$. With simulation, plots of irradiance versus MPP voltage and plots of irradiance versus power loss are illustrated in Figs. 16 and 17, respectively. The power loss due to the limited operating voltage range is about $0-4 \%$, and the maximum power loss under $600 \mathrm{~W} / \mathrm{m} 2$ and $60 \circ \mathrm{C}$ is $3.84 \%$. It is important to ensure that the MPP voltage range of a PV array can fit the limited operating voltage range, which can prevent deviation from the MPPs and reduce the power loss. According to the $\mathrm{P}-\mathrm{V}$ characteristics of the aforementioned

\section{Conclusion}

This paper has presented numerical analysis with MATLAB to simulate the power loss caused by deviation from the MPPs which are due to the loss factors of DLFVR, fast irradiance variation + DLFVR, fast dc load variation + DLFVR, limited operating voltage range + DLFVR, and overall combination for both singlestage and two-stage GCPVS. Analysis and simulation procedure of the power loss has been described, which provides engineers a guideline for building a model of PV array and performing the power loss analysis. According to the loss analysis, the total power loss in a single-stage GCPVS is close to a two-stage GCPVS, while the single-stage one can save a stage of a boost converter. That is, from a viewpoint of efficiency, cost, and system size, a single-stage GCPVS is feasible in dc-distribution and grid-connected applications if the operating voltage range is properly selected. It has been also verified .

\section{References}

[1]. T.-F. Wu, C.-H. Chang, Y.-D. Chang, and K.-Y. Lee, "Power loss analysis of grid-connection photovoltaic systems," in Proc. Power Electronics and Drive Systems (PEDS) Conf., 2009, pp. 326-331.

[2]. T. A. Huld, M. Suri, R. P. Kenny, and E. D. Dunlop, "Estimating PV performance over large geographical regions," in Proc. 31st IEEE. Photovoltaic. Spec. Conf., 2005, pp. 1679-1682.

[3]. N. Okada, S. Yamanaka, H. Kawamura, and H. Ohno, "Diagnostic method of performance of a PV module with estimated power output in considering four loss factors," in Proc. 31st IEEE Photovoltaic. Spec. Conf., 2005, pp. 1643-1646.

[4]. R. Suzuki, H. Kawamura, S. Yamanaka, H. Ohno, and K. Naito, "Lossfactors affecting power generation efficiency of a PV module," in Proc.29th IEEE. Photovoltaic. Spec. Conf., 2002, pp. 1557-1560.

[5]. N. Okada, S. Yamanaka, H. Kawamura, and H. Ohno, "Energy loss of photovoltaic system caused by irradiance and incident angle," in Proc.3rd IEEE Photovoltaic Energy Convers. World. Conf., 2003, pp. 2062-2065. 
[6]. Y. Ueda, K. Kurokawa, T. Itou, K. Kitamura, Y. Miyamoto, M. Yokota,and H. Sugihara, "Performance ratio and yield analysis of grid connected clustered PV systems in Japan," in Proc. 4th IEEE Photovoltaic Energy Convers.World. Conf., 2006, pp. 2296 2299.

[7]. W.-M. Wu, X.-L. Wang, P. Geng, and T.-H. Tang, "Efficiency analysis for three phase grid-tied inverter," in Proc. IEEE Ind. Technol. Int. Conf.(ICIT), 2008, pp. 1-5.

[8]. T. Oozeki, K. Otani, and K. Kurokawa, "An evaluation method for PV system to identify system losses by means of utilizing monitoring data," in Proc. 4th IEEE Photovoltaic Energy Convers. World Conf., 2006,pp. 2319-2322.

[9]. N. A. Ninad and L. A. C. Lopes, "Operation of single-phase grid-connectedinverters with large DC bus voltage ripple," in Proc. IEEE Energy Power and Control (EPC), 2007, pp. 172-176.

[10]. G. Ertasgin, D. M. Whaley, N. Ertugrul, and W. L. Soong, “Analysis and design of energy storage for current-source 1-ph gridconnected PV inverters,” in Proc. 23rd Annu. IEEE Appl. Power Electron. Conf. (APEC),2008, pp. 1229-1234. 